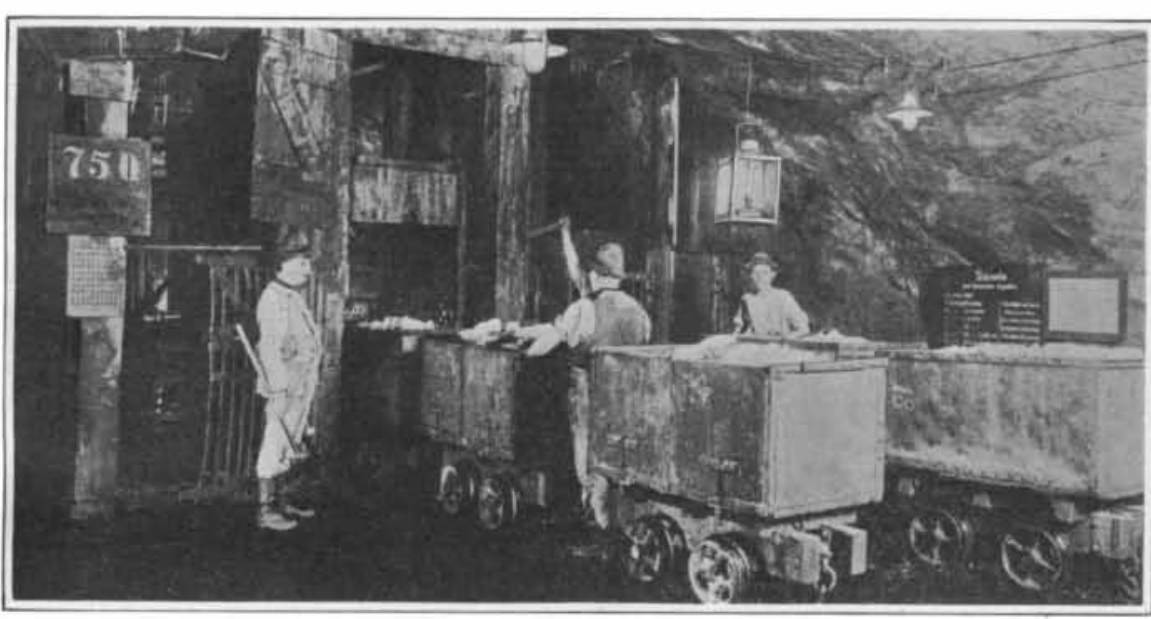

At the foot of a shaft in a potash mine.

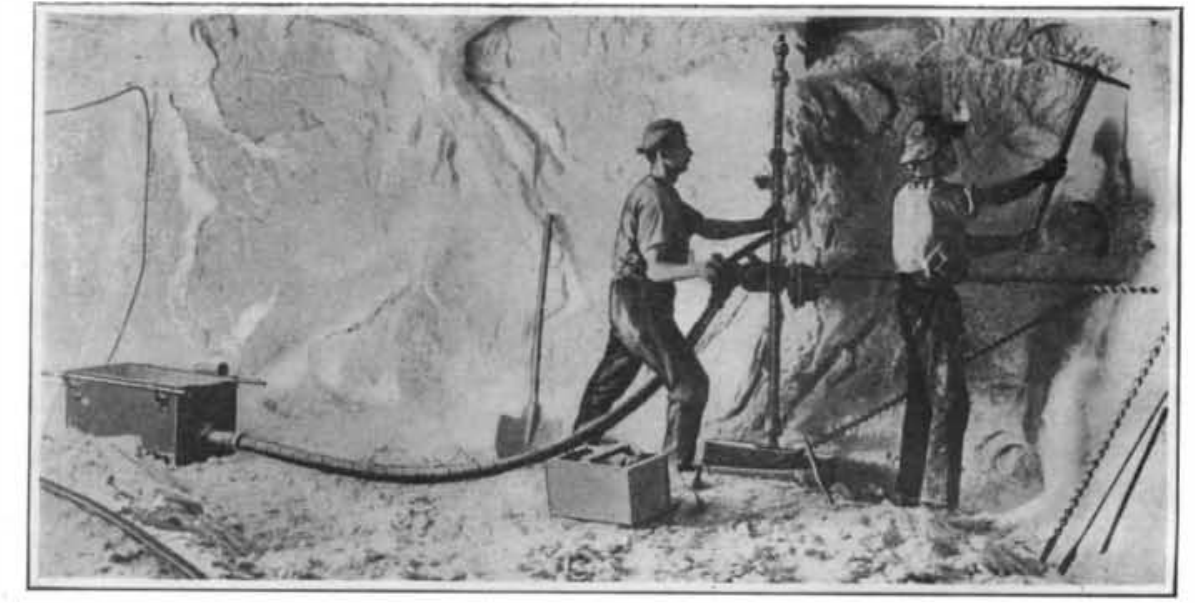

Mining potash with an electrically driven drill.

\title{
The German Potassium Salts
}

\section{A Fertilizing Material Indispensable to the Agriculturists of the World}

\author{
By Dr. Alfred Gradenwitz
}

Tre remarkable standing of German agriculture is due to the assistance of a highly developed science rather than to the excellence of the soil or the advantages of privileged climate. In fact, Nature, in Germany, has, in both respects, been rather sparing of her bounties However, the country possesses one treasure of inestimable value, viz., its deposits of potassium salts, which are not found in any appreciable amounts outside Germany, and on which the agriculture of the world is, to many, and on which the
some degree, dependent.

some degree, dependent.
The present state of temporary national isolation, following on a period of practically unlimited exchange lends additional interest to the potassium salt problem some aspects of which are discussed in the following:

The potash in plants serves to produce and convert carbo-hydrates--starch, sugar and cellulose-from the carbonic acid of the air (absorbed by the leaves) and from the water supplied by the roots. In the absence of potash, starch and sugar are only formed insufficiently, and the yield of cereals, potatoes, etc., remains far below the average.

A skilled eye recognizes at a glance whether a plant does not receive its proper potash supply. There is, at first, a luxurious development of the leaves, so that superficial observers are inclined to deny the importance of potassium fertilizers. This, however, is at a later stage followed up by an absolute standstill in the development of the leaves and by premature withering. velopment of the leaves and by premature withering. soon afterward, the remainder of the plant, will di prematurely. In a test made at the Bernburg Experimental Station, the sugar contents of a beet-root would decrease from 16 to 8 per cent. On the other hand, an adequate supply of potassium salts not only further the production of those materials for the sake of which most agricultural but increase the resistance of plants against animal and vegetable pests, as well as against freezing.

The amount of potash required hy different kinds of plants varies enormously. Some--e. g., barley an wheat--are contented with very small quantities, whil others-e. g., rye, oats, potatoes, beets, many leguminous plants and tobacco-are very exacting in this respect. Again, there are many kinds wbich, though satisfied with small amounts, require their potash in a soluble form, ete.

All soils containing less than 0.2 per cent of potash will benefit from fertilization with potassium salts. Thi will benefit from fertilization with potassium salts. This
applies, apart from sand, to all marshy soils. Sandy applies, apart from sand, to all marshy soils. Sand
loam also, in most cases, requires a potash supply, in opposition to an opinion largely prevalent among agr culturists. Special fertilizing tests should be referred to in order to ascertain whether or not a given culture requires an addition of potash to its soil. Such tests, however, are readily made even by the smallest farmer.

The German potassium salt deposits were formed by gradual settling in a branch of the ocean which, once upon a time, covered a large portion of Northern Germany. When the saturation of the brine had reached a certain degree, the least soluble salts, viz., carbonat and sulphate of lime, would be the first to separate while the sodium, potassium and magnesium salts still romained in solution, there being a continued, though not regular, water supply from the ocean. As, however, not regular, water supply from the ocean. As, however, evaporation advanced, the main part of the rock salt
separated in its turn, thus becoming the mighty base of all present potash beds. The mother-lye now contained, besides sodium compounds, only magnesium and potassium salts, wbich concentrated the more rapidly as the ligh temperatures and violent storms activated evapora tion. Magnesium sulphate was the first to separate in what is known as the Kieserite region, above which the potash at last settled in a double salt of potassium and magnesium chlorides, mixed with some sodium chloride and kieserite. This double salt, known as carnallite, constitutes the main component of the more important potassium salt deposits and is found in inexhaustible amounts throughout Northern Germany.

The potassium salt deposits eventually became covered with an air and water tight coating of fine clay, on which a thick layer of substantial sand and clay settled in course of time. Great variety was, however, produced in the composition and arrangement of the salt beds by the water entering through any fissures. Apart from

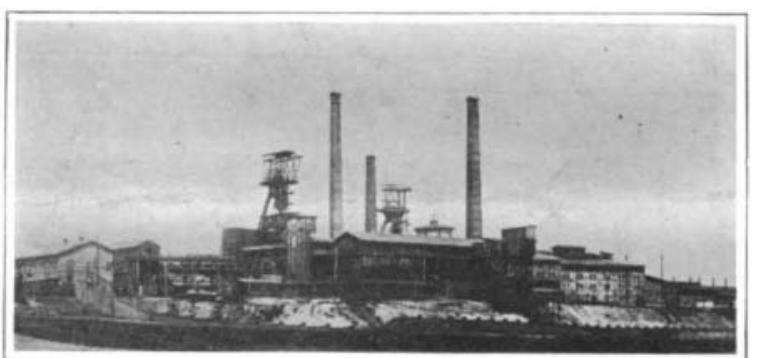

Surface works at a German potash mine.

carnallite, there are some other potassium minerals of importance to the agriculturist, viz., hard salt, produced from carnallite by the action of water, washing away the magnesium chloride; sylvinite, another product of carnallite, freed also of its kieserite and kainite, in connection with which only magnesium chloride has been washed out.

The carnallite, kainite, hard salt, and sylvinite are blasted out of the deposits, 1,000 to 3,000 feet in depth, by means of explosives, after which they are taken to the surface in cages and ground to fine powders immediately suitable for use as fertilizers. From carnallite there are, however, also made by artificial processesdissolving, crystallizing and drying-special fertilizers containing a high percentage of potash, of which a 40 per cent potassium salt is of growing importance for German agriculture.

The German potassium industry was, of course, deeply affected by the outbreak of the present war. Exports to the United States, which of late years amounted to about $\$ 14,000,000$, decreased immediately very conside rably, because the German shipping companies had to discontinuo their service, while neutral lines could not offer sufficient cargo space for the quantities of potassium salts which had been ordered. Moreover, the German gov wh had been ordered. Moreover, the Cerman government issued a temporary export prohibition, which was not removed until the end of September. In fact,
only 60,000 tons could be exported to the United States in the months from August to December, inclusive, while 578,000 tons had been shipped in the corresponding period of the previous year. This resulted in a serious shortage of potassium salts, and the prices of potassium chloride rose from $\$ 38$ to $\$ 42$ to $\$ 80$, and even $\$ 120$ per ton. Such prices, however, could only be paid by chmi cal work, and not by agricultural cone cal works, and not by agricultural concerns. At the end of January last, the export prohibition was renewed,
thus bringing shipments to a standstill, so that fancy prices of up to $\$ 200$ per ton were demanded. This state of affairs is the more inconvenient as potassium salts cannot be dispensed with for the cultivation of the most important crops of North America, such as cotton, tohaceo, sugarcane, corn, fruit, and many other vegetables. There are at present 193 potassium salt works in operation in Germany, while another 100 are being erected. These represent an invested capital of upward of $\$ 400,000,000$, and are combined in what is known as the Potassium Syndicate (Kalisyndikat), Ltd., with beadquarters in Berlin. In mining and in factories the German potassium industry employs about 2,600 persons in various positions, as well as 45,000 workmen. About 2,200 boilers produce the more than 350,000 horsepower required for a total of 2,700 engines. The average daily production, in normal times, amounts to 3,870 carloads, each of ten tons, and rises at times of brisk business, in spring and autumn, to 6,000 carloads.

The Potassium Syndicate embraces the whole world in its business operations. It has everywhere abroad its own representatives, and in all important countries its own experts, whose task consists of instructing farmers in the proper way of using the salts. The potassium industry also embraces the world literally, in so far as the sar.ks required for last vear's snipments, if placed in a row, would reach more than twice round the equator.

The following table shows the amount of potassium salts used per square kilometer of tillable land in Germany and the United States, respectively, and strikingly illustrates the rapid advance in the course of the last few years:

\begin{tabular}{c|c|c}
\hline Year. & German Empire. & United States. \\
\cline { 2 - 3 } $1890 \ldots \ldots \ldots \ldots \ldots \ldots \ldots \ldots \ldots \ldots \ldots$ & $68 \mathrm{lbs}$. & $12 \mathrm{lbs}$. \\
$1900 \ldots \ldots \ldots \ldots \ldots \ldots$ & 1,364 “ & 30 “" \\
$1913 \ldots \ldots \ldots$ & 107. \\
\hline
\end{tabular}

With the increased use of potassium in Germany, there was, of eourse, connected a
in the avcriuge anmual yields.

\section{Mica from India}

According to the Engincer, the Hazaribagh district in India is one of the most valuable mica-producing areas in the world. Except for a very small amount from Sweden, all the "ruby" mica comes from Chota Nagpur, and India yields more than half the world's output of mica generally. The country where it is found is of a jungly nature, and this renders observation of the prospecting coolies a difficult matter. These coolies scoop away the earth and find the mica generally at a comparatively small depth from the surface. It is then in irregular lumps, usually not more than 1.2 inches to 15 inches long, and 6 inches or 8 inches thick. This is split into scales or laminae. Large sheets are the most valuable, and a piece 30 inches scluilre would probably fetch 100 rupees. When split intu sheets it is classified according to size and packed in what are known as books. It is then ready for export. According to the Pioncer Mail, however, it is very seldom that a large sheet finds its way to the owners of the land on which it is discovered. The coolie usually hides it in the ground, and subsequently sells it to an agent. The nearest parallel to what occurs is found in illicit diamond buying in Kimberley and other parts of South Africa. Although the expenses incurred in working mica are extraordinarily small, the business does not pay if no large "bonks" are obtained. Consequently, if a firn is consistently being robbed of its hest finds, if naturalfs falls, and this is the reason for the failune of wang firms. 

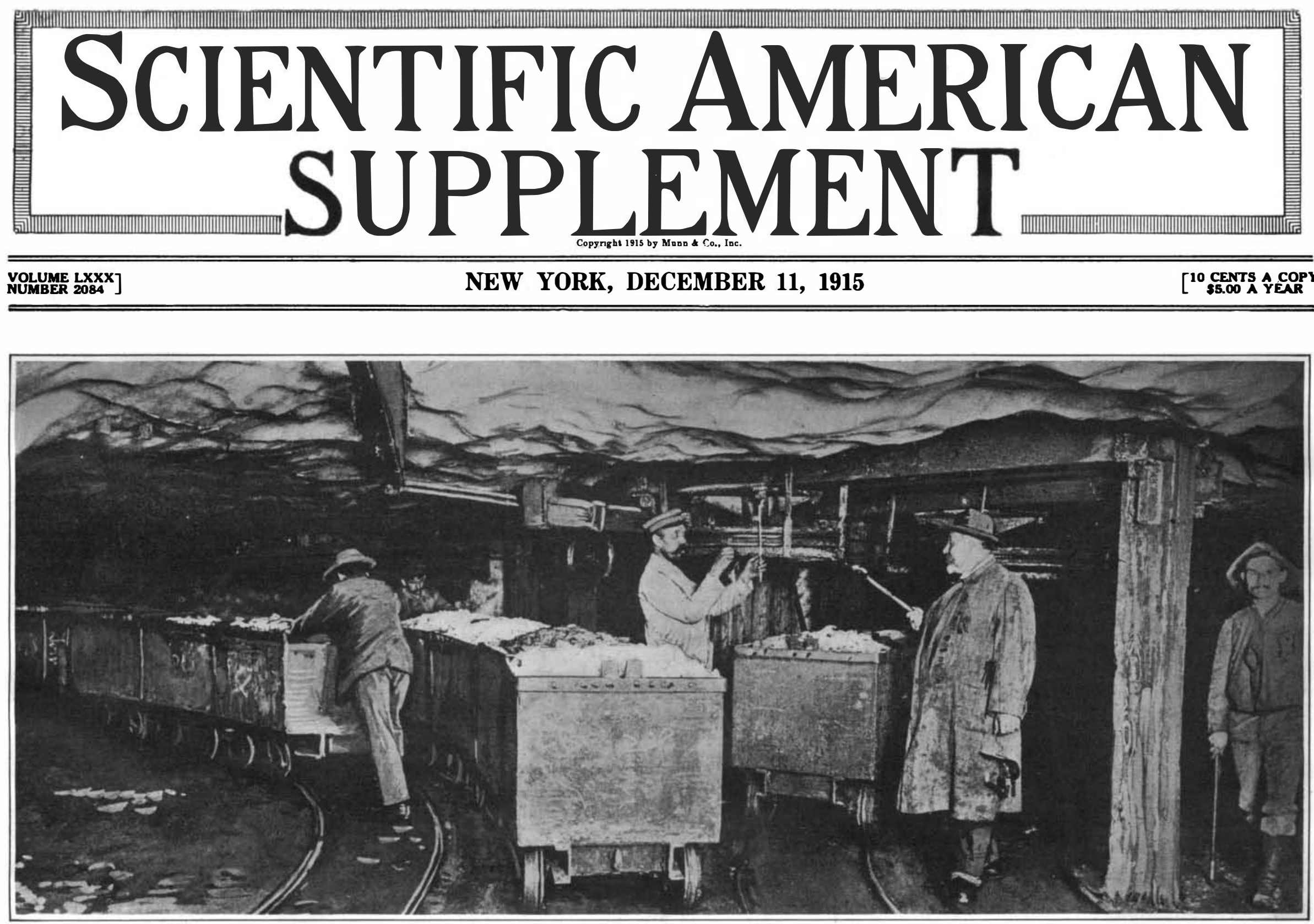

Ropeway hauling trucks in German potash mine.

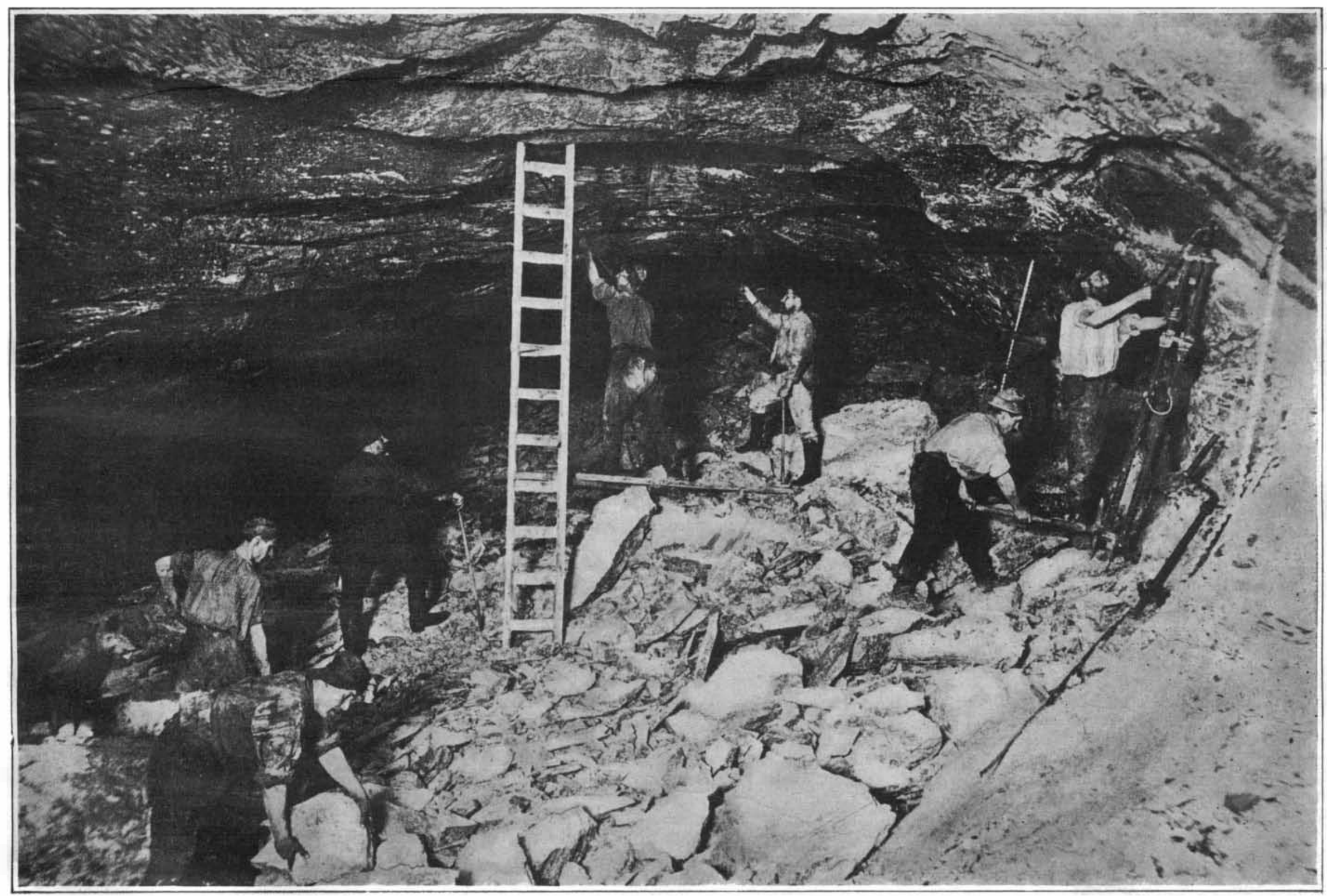

Working kainite in a German potash mine.

THE GERMAN POTASSIUM SALTS.-[See page 372.] 